Int. J. Electrochem. Sci., 12 (2017) $3991-4000$

\title{
Preparation of Cobalt/Coal-Based Activated Carbon Composites with Synergistic Electrochemical Performance
}

\author{
Junsheng Zhu, ${ }^{1, *}$ Xu Zhang ${ }^{1}$, Shuangquan Zhang ${ }^{1}$, Dianlong Wang $^{2}$ \\ ${ }^{1}$ School of Chemical Engineering and Technology, China University of Mining and Technology, \\ Xuzhou 221116, China \\ ${ }^{2}$ School of Chemical Engineering and Technology, Harbin Institute of Technology, Harbin 150001, \\ China \\ *E-mail: zhujschina@ 163.com
}

doi: $10.20964 / 2017.05 .43$

Received: 23 February 2017 / Accepted: 16 March 2017 / Published: 12 April 2017

\begin{abstract}
A facile precipitation approach has been developed to prepare cobalt/coal-based activated carbon composites as an electrode material for supercapacitors. The existence of coal-based activated carbon facilitates the dispersion of Co particles. The electrochemical performance of Co/coal-based activated carbon composites had been characterized by cyclic voltammetry, galvanostatic charge/discharge tests and electrochemical impedance spectroscopy. The specific capacitance of the as-prepared composite material approaches $615 \mathrm{~F} \mathrm{~g}^{-1}$ at a current density of $2 \mathrm{~A} \mathrm{~g}^{-1}$. And the composite electrode delivers an excellent rate capacity of $495 \mathrm{~F} \mathrm{~g}^{-1}$ even at a current density as high as $20 \mathrm{~A} \mathrm{~g}^{-1}$. The impressive performance could be ascribed to the synergistic effect of the combination of the pseudocapacitive cobalt nanoparticles and the coal-based activated carbon matrix.
\end{abstract}

Keywords: Cobalt; Coal-based activated carbon; Supercapacitors; Composites

\section{FULL TEXT}

(C) 2017 The Authors. Published by ESG (www.electrochemsci.org). This article is an open access article distributed under the terms and conditions of the Creative Commons Attribution license (http://creativecommons.org/licenses/by/4.0/). 